\title{
Hardware Implementation of a Communication Link for 5G Communication in the Tropical Regions
}

\author{
Trilochan Patra, Swarup Kumar Mitra
}

\begin{abstract}
The 5G communication system comprises various ingredients essential for the recent radio access network. The $5 G$ wireless technology can open a greater scope for device manufactures and application developers. In this paper a communication link model has been designed and implemented for $5 G$ communication for the tropical regions. Spatial Diversity Technique has been used to design the communication link model. This model has also been designed using Xilinx system generator and implemented utilizing FPGA kit. As a result, the bit error rate (BER) of the signal gets attenuated from the transmitter as well as from the receiver portion of the aforesaid model. This model relies on the samples per frame, M-Aray number and number of transmitting antennas for rate $3 / 4$ at the transmitter section. It also depends on the computation delay; receive delay, number of receiving antennas for rate $3 / 4$ at the receiver portion. The channel frequency is based on the $5 G$ communication frequency ranging from $600 \mathrm{MHz}$ to $100 \mathrm{GHz}$.
\end{abstract}

Keywords: Convolution coding technique, Viterbi decoding technique ,Digital Modulation Technique, MIMO Technique, Rain Attenuation Channel.

\section{INTRODUCTION}

Currently, 5G communications has been announced by researchers in a strict tone that it is part and parcel of modern technology as well as a major challenge to incorporate modern civilization into wireless communication. 5G communication in modern technology demands much higher data rates, higher network capacity, wider spectral efficiency and higher mobility. 5G communications use millimeter wavelengths and these wavelengths are shorter than $3 \mathrm{G}$ and $4 \mathrm{G}$. Its signal may bear more data when 5G communication covers a shorter distance. A typical user-centered $5 \mathrm{G}$ communication is shown in fig. The 1 millimeter (mm) waveform is to be used extensively to withstand the broad bandwidth requirement and installation of MIMO (multiple-input and multipleoutput)

systems. The rain fades into electromagnetic waves through the process of absorption and dispersion [1] [2].Again the disappearance of rainfall occurs in proportion to the rate of rainfall and frequency. This event causes a lot of path loss,

Revised Manuscript Received on February 05, 2020.

* Correspondence Author

Trilochan Patra*, Department of ECE, Techno International Newtown, Rajarhat, kol-700156,India.trilochanpatra266@gmail.com

Swarup Kumar Mitra, Department of ECE, MCKV Institute of Engineering,Liluah,Howrah-711204,India

(C) The Authors. Published by Blue Eyes Intelligence Engineering and Sciences Publication (BEIESP). This is an open access article under the CC BY-NC-ND license (http://creativecommons.org/licenses/by-nc-nd/4.0/) restricts the transmission area and, as a result, reduces the execution of the said event conformance. The ITU-R is an organization that streamlines the rule for telecommunications and supplies a step by step motion for forecasting rainfall attenuation on a portion of terrestrial radio links. The ITU-R model does not work efficiently in the tropics [3] because in high rainfall rate regions, that is, the average radius of rainfall in the tropics does not correlate with the tropics and the data for the ITU model is dependent on the Earth's temperate climate. Data obtained from [4]. Using radio frequencies in the microwave and millimeter wave bands requires an increased data rate and greater bandwidth claims for a system. With the increase in rain rate, quenching in radio links also increases and this process shows negative effects on microwave and millimeter frequencies as EM waves are mostly affected by absorption [5-7] and dispersion events. The main cause of attenuation at high altitudes of the atmosphere is the scattering of Rayleigh and Mai. To design communication links, various parameters have to be considered. These parameters should be accurate systems, low cost design, choice of current and incoming frequency, site design and multilevel systems. Path loss due to rain fading has been identified as an excellent inhibitor for designing communication links that perform at frequencies greater than $10 \mathrm{GHz}$ [8]. In tropical regions of South-East Asia, where excessive rainfall is a common feature throughout the year and a small area is often covered in the rate of precipitation, the mitigation of rainfall appears prominently in the production of loss and millimeter-wave. And can cause a lot of destruction for microwave signals. The rain fade reduces the performance of the system and restricts the use of high frequencies to the terrestrial line of sight communication system. As discussed earlier, path quenching plays an important role when heavy frequencies exceed $10 \mathrm{GHz}$. keeping all these factors in mind; it is clear that abatement due to rain should be unavoidable [9-12].

The attenuation on a particular path depends on the utility of frequency, polarization, temperature, path length and latitude [13]. The mitigation factor due to rain is one of the main criteria for mobile communication designers. Now research work for high speed $5 \mathrm{G}$ communication systems is rapidly evolving to enrich wireless communication systems. For this reason the requirement of mass bandwidth, lack of frequency spectrum below $5 \mathrm{GHz}$, millimeter wave (mmwave) spectrum has largely taken place. Now wireless communication system is gradually coming towards the application of millimeter wave ( $\mathrm{mm}$ wave) frequency spectrum and hence mobile service providers feel the need for very high data rates [1]. 
With the increase in demand for Cellular communication fifth generation (5G), cellular systems utilizing the MM wave spectrum have appeared boldly to provide large data holding rates. So $5 \mathrm{G}$ cellular communication is much better than the four previous generations (1G, 2G, 3G and 4G). The need for high carrier frequencies of $28 \mathrm{GHz}$ and above in particular includes strong diffusion destruction due to rain, the effects of which are harmful in areas with heavy rainfall [3]. In this regard, when radio waves pass over a rainy region, the immersion and scattering of electromagnetic waves provide outstanding path loss because the physical dimensions of the rain drops are of the same order. In fact, rainfall mitigation depends on frequency as well as wave propagation. Precipitation is the main barrier that restricts the reproduction of mm-wave signals from the transmitter to the receiver. The signals brought forward by the mm-wave can be distributed, dispersed, depolarized and delivered by rain. This phenomenon limits the propagation of mm-wave signals, and brings about excessive signal quenching losses through the fruitful multiplication path length $(\mathrm{km})$ marked in $\mathrm{dB} / \mathrm{km}$ [14-17]. Effective multiplication path length is the natural path length of a microwave connection between the transmitter and receiver. The result is more binding in tropical regions where rainfall intensity is higher and rainfall size is larger. According to climate change, the size distribution of rainfall varies. Radio mm-waves can also be of similar size according to climate change. The aforementioned geophysical phenomena can significantly control the propagation of mm-wave signals, which leads to high quenching loss of the signal along the resultant multiplication path. Precipitation mitigation is severely enhanced as rainfall density increases by diffusion and frequency.

In this paper a hardware model of rainfall attenuation is designed and implemented using Xilinx system generator and FPGA kit. This model shows that various parameters such as M-Aray number, sample per frame, number of antennas, computation delay, delay received can be reduced. If the bit error rate is minimal, the signal attenuation is also minimal. Section I indicates the introduction, Section II depicts the work flow of the proposed model, Section III displays the model description. Sections IV and V contain the results and conclusions, respectively. In fine, references are described in section VI.

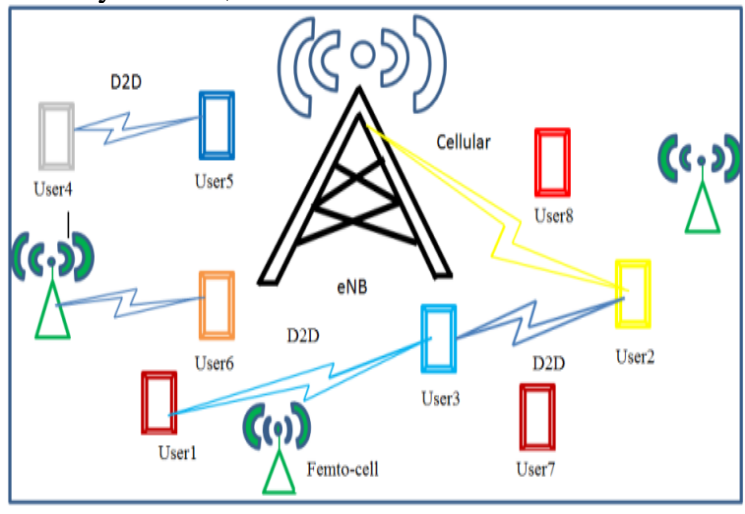

Fig.1. A generic user centric 5G communication

\section{WORK FLOW OF THE PROPOSED MODEL}

In previous research work [36] [37] hardware models of transmitters and receivers have been used for channel characterization and channel characterization of mm-wave bands during rainfall in tropical regions. But it has been observed from previous research work that no work has been done for bit error rate minimization technique in tropical regions and no hardware model has been designed for BER minimization for $5 \mathrm{G}$ communication. Therefore to design and implement the model shown in Fig.6, the following techniques have been adopted. A flow chart is given below in this regard-

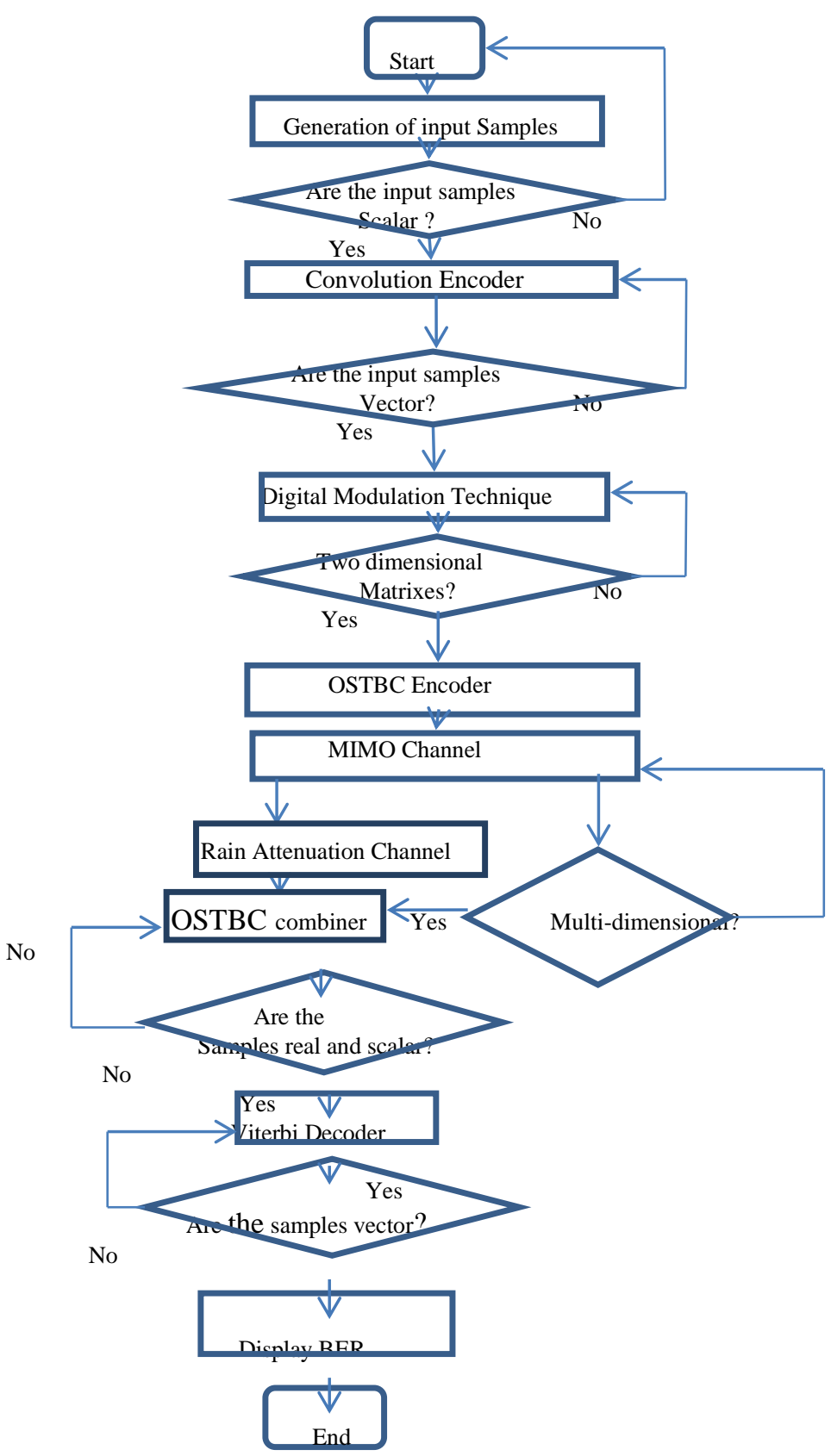

The main techniques adopted in the work flow for the proposed model are briefly described below:-

\section{A. Convolution Coding Technique}

As the convolutional codes are very convenient in character, the digital data communication from arbitrary errors because of any source of noise can be defended very easily. It attains error free communication by addition of affluent redundancy to the source symbols.

Convolutional codes are generally defined by applying two criteria: - the

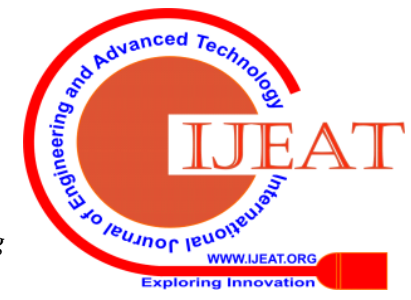


code rate and the constraint length.

The code rate is defined as a ratio between the numbers of input symbols $(\mathrm{k})$ into the channel encoder and the number of output symbols (n) by the channel encoder in a given loop. The code rate is defined as, $\mathrm{r}=\mathrm{k} / \mathrm{n}$ bits/symbol. A convolutional encoder makes proceedings of continuation of the message. The n-bit encoder output at a definite time relies not only on the continuation of the K-bit message, but also on the first $\mathrm{m}$ input block. A set of sequences emanating from $k$ - input and n-output encoder of memory order $m$ is known as $(n, k, m)$ convolutional code. The value of $n$ and $k$ is much lower for constitutional codes than for block codes.

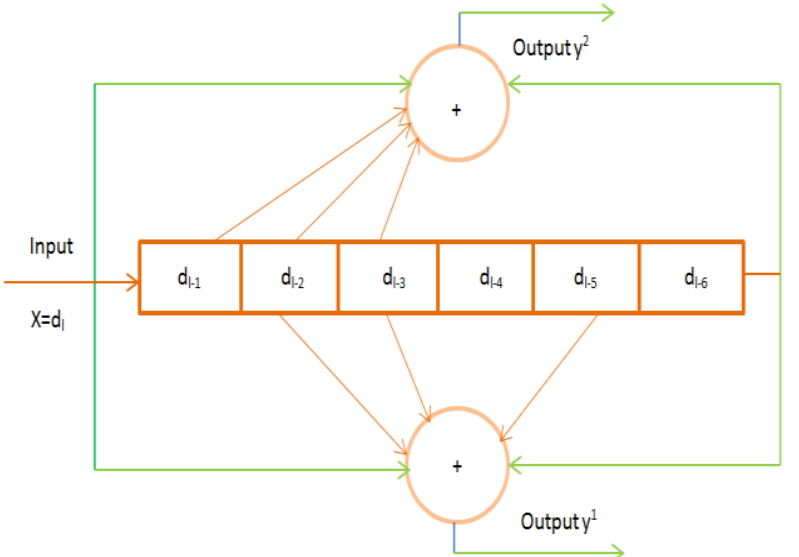

Fig. 2. Convolution encoder for constraint length $(K)=7$, bit rate $(r)=1 / 2$

\section{B. Spatial diversity technique}

The spatial diversity technique is also called antenna diversity. The said antenna diversity uses two or more antennas to enrich the condition and authenticity of a wireless connection. Generally there exists no specific line of sight between the transmitter and receiver in urban and indoor surroundings. More truly, the signal is thrown back along multiple paths before it is received ultimately. Space diversity provides a better result for minimizing these multipath positions as at the receiver side there are a number of antennas to accept the various copies of the identical signal. There are two types of spatial diversity technique. They are given below-

- Transmit Diversity: Transmit diversity technique uses more than one transmitting antenna and one receiving antenna.

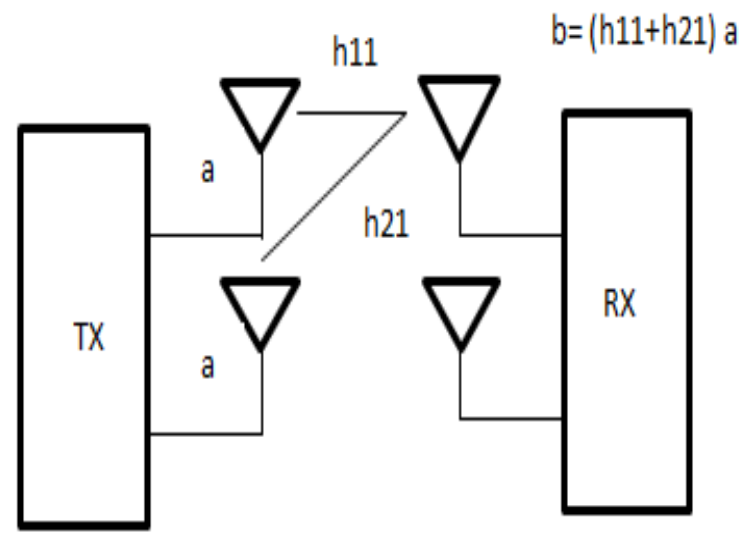

Fig. 3. Transmit Diversity

- Receive Diversity: Receive diversity technique uses one transmitting antenna and more than one receiving antenna.

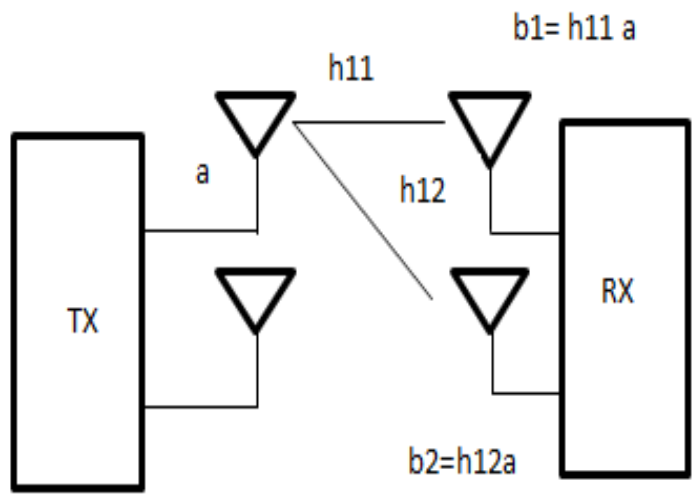

Fig. 4. Receive Diversity

\section{Digital Modulation Technique}

In the digital modulation technique an analog signal is modulated with a binary code. The digital modulator device produces coherence lying between the transmitter and the channel. The digital modulation can be categorized chiefly supporting the bandwidth characteristics of compression. The primary standards for the best modulation method rely on Signal to Noise Ratio (SNR), proficiency of supply of electricity, accessible bandwidth, and service of standard quality, Bit Error Rate (BER), profitability [8]. The attainment of each modulation process is computed by the estimation of the probability of error with the presumption that a system carries on with Additive White Gaussian Noise [9]. The basic types of digital modulation methods are Phase Shift Keying (PSK), Frequency Shift Keying (FSK), and Amplitude Shift Keying (ASK) respectively [12-14].

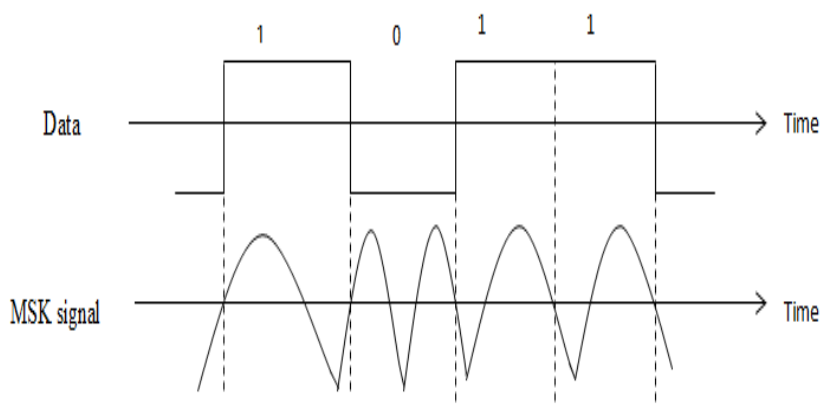

Fig. 5. Signal Using MSK Modulation

\section{MODEL DESCRIPTION}

The model shown in fig. 6 relates to the diversity technique which is to be utilized for Bit Error Rate Minimization in the tropical regions in respect of $5 G$ communications. It is devised so that it may operate up to $100 \mathrm{GHz}$ frequency.

In this model, convolution encoder, Viterbi decoder, Gateway In and Gateway Out are included within Xilinx block set. This model also contains Simulink block set wherein lie random Integer generator, M-PSK Modulation Technique, Alamouti code, MIMO channel, rain attenuation channel, squeeze, Error Rate Calculation.

Using random integer generator block the samples per frame of a signal are produced. These samples pass through the unbuffer block which converts a frame into scalar samples output at a higher rate. 
These samples of scalar form pass through the convolution encoder.

These samples are now encoded using convolution encoder. The constraint length, convolution code and output rate have been setup inside the convolution encoder block. Now the samples are again converted from scalar form into vector form with the help of buffer block. The vector forms of samples pass through the M-PSK modulator baseband. This block modulates the input signal using the phase shift keying method. The input signal may be either bits or integers. Now the samples are converted into a two dimensional matrix form using 1-D to 2-D converter. Then the samples cross over the OSTBC encoder block encoding the input message using an orthogonal space-time block code (OSTBC). The OSTBC is of rate 1 for 2 transmit antennas. The rate has been considered $1 / 2$ or $3 / 4$ for 3 and 4 transmit antennas. The input must be either a column vector of length $\mathrm{N}$ or a full 2-D matrix with $\mathrm{N}$ columns. For a full matrix input, the rows are encoded independently with the help of the encoder. $\mathrm{N}$ is chosen to be a multiple of 2 if the OSTBC is for 2 transmit antennas or holds rate $1 / 2$.Again $N$ is chosen to be a multiple of 3 if the OSTBC holds rate $3 / 4$. It appears that from the output of OSTBC encoder the samples pass through the MIMO channel and rain attenuation channel. The MIMO channel separates the input samples of the signal through a MIMO multipath fading channel. When the samples propagate along the rain attenuation channel, the samples of the signal are attenuated on account of rain. When the samples complete passing through the MIMO channel, these samples enter the squeeze block which removes singleton dimensions of multi-dimensional input signal. A singleton dimension is defined as a dimension holding size 1 . As for example, a 2x1x3 signal becomes a $2 \times 3$ signal. Now the samples take place in the OSTBC combiner block which combines the received signal and channel estimate inputs in accordance with the structure of the orthogonal space-time block code (OSTBC). For one receive antenna, the received signal input must be either a column vector or a full 2-D matrix. Correspondingly, the channel estimate input must be a full 2-D or 3-D matrix. For more than one receive antenna, the received signal input must be a full 2-D or 3-D matrix. Thereafter, the channel estimate input must be a 3-D or 4-D matrix. Here the samples enter the 'complex to real image block' which changes a complex signal into a real one. The samples now get in the Viterbi decoder along the unbuffer block. The Viterbi decoder utilizes the Viterbi algorithm to

decode input data encoded convolutionally. Now the samples take shelter in the Error Rate Calculation block which measures the error rate of the data received by comparison of it with a delayed version of the transmitted data. The block output is a vector of three elements comprising the error rate. This system is followed by the number of detected errors and the total number of symbols compared. This vector may be transmitted either to the workspace or to an output port. The delays are identified in number of samples. Anyhow, it is not bothered whether the input signal belongs to scalar form or vector one. The inputs belonging to ' $\mathrm{Tx}^{\prime}$ and ' $\mathrm{Rx}$ ' ports must be of scalar form or column vectors. In the long run, in display block the numeral output of the input values has been noticed. In the display block the BER values have been reflected.
The Bit Error Rate values have been changed by altering the samples per frame values, M-array number values in the random integer generator block in the transmitter portion. The BER values have also undergone change by altering the computation delay and receive delay values in the Error Rate calculation block in the receiver portion. Otherwise the BER values will remain unchanged. The following model demonstrates the communication link using system generator:-

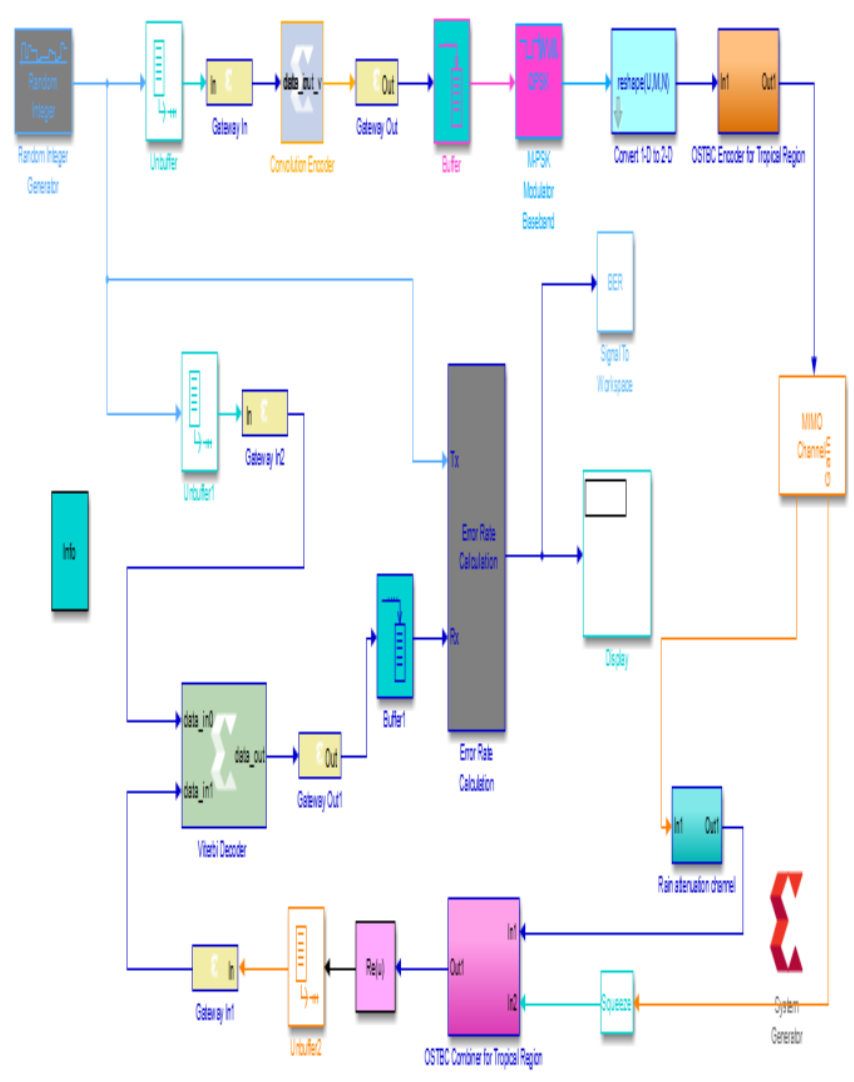

Fig. 6. Communication link model using system generator

Variation of BER for different parameters are shown in the table 1 below-

Table- I: Variation of bit error rate for different parameters

\section{PARAMETERS}

\begin{tabular}{|c|l|l|l|l|l|l|}
\hline $\begin{array}{l}\text { Sampl } \\
\text { es per } \\
\text { frame }\end{array}$ & $\begin{array}{l}\text { M-ary } \\
\text { numbe } \\
\mathbf{r}\end{array}$ & $\begin{array}{l}\text { No of Tx } \\
\text { antennas } \\
\text { and rate } \\
\mathbf{3 / 4}\end{array}$ & $\begin{array}{l}\text { No of } \\
\text { Rx } \\
\text { antenna } \\
\text { s and } \\
\text { rate 3/4 }\end{array}$ & $\begin{array}{l}\text { Compu } \\
\text { tation } \\
\text { Delay }\end{array}$ & $\begin{array}{l}\text { Receive } \\
\text { Delay }\end{array}$ & BER \\
\hline 50 & 2 & 2 & 2 & 15 & 20 & 0.4667 \\
\hline 100 & 2 & 2 & 2 & 15 & 20 & 0.5846 \\
\hline 200 & 2 & 2 & 2 & 15 & 20 & 0.5333 \\
\hline 400 & 2 & 2 & 2 & 40 & 50 & 0.4968 \\
\hline 800 & 2 & 2 & 2 & 50 & 60 & 0.4913 \\
\hline 1600 & 2 & 2 & 2 & 80 & 90 & 0.4825 \\
\hline 2000 & 2 & 2 & 2 & 80 & 90 & 0.4809 \\
\hline 4000 & 2 & 2 & 2 & 110 & 120 & 0.4942 \\
\hline 50 & 4 & 2 & 2 & 15 & 20 & 0.8667 \\
\hline 100 & 4 & 2 & 2 & 15 & 20 & 0.8308 \\
\hline 200 & 4 & 2 & 2 & 15 & 20 & 0.7455 \\
\hline
\end{tabular}




\begin{tabular}{|c|c|c|c|c|c|c|}
\hline 400 & 4 & 2 & 2 & 40 & 50 & 0.7290 \\
\hline 800 & 4 & 2 & 2 & 50 & 60 & 0.7319 \\
\hline 1600 & 4 & 2 & 2 & 80 & 90 & 0.7336 \\
\hline 2000 & 4 & 2 & 2 & 80 & 90 & 0.7306 \\
\hline 4000 & 4 & 2 & 2 & 110 & 120 & 0.7393 \\
\hline 50 & 8 & 2 & 2 & 15 & 20 & 0.9333 \\
\hline 100 & 8 & 2 & 2 & 15 & 20 & 0.8923 \\
\hline 200 & 8 & 2 & 2 & 15 & 20 & 0.8667 \\
\hline 400 & 8 & 2 & 2 & 40 & 50 & 0.8806 \\
\hline 800 & 8 & 2 & 2 & 50 & 60 & 0.8725 \\
\hline 1600 & 8 & 2 & 2 & 80 & 90 & 0.8853 \\
\hline 2000 & 8 & 2 & 2 & 80 & 90 & 0.8798 \\
\hline 4000 & 8 & 2 & 2 & 110 & 120 & 0.8790 \\
\hline 150 & 2 & 3 & 3 & 15 & 20 & 0.5391 \\
\hline 300 & 2 & 3 & 3 & 15 & 20 & 0.5057 \\
\hline 600 & 2 & 3 & 3 & 30 & 40 & 0.5000 \\
\hline 900 & 2 & 3 & 3 & 40 & 50 & 0.4963 \\
\hline 1200 & 2 & 3 & 3 & 40 & 50 & 0.4982 \\
\hline 1800 & 2 & 3 & 3 & 50 & 60 & 0.4846 \\
\hline 2400 & 2 & 3 & 3 & 60 & 70 & 0.4836 \\
\hline 3600 & 2 & 3 & 3 & 70 & 80 & 0.4916 \\
\hline 4200 & 2 & 3 & 3 & 80 & 90 & 0.4935 \\
\hline 600 & 4 & 3 & 3 & 30 & 40 & 0.7434 \\
\hline 1200 & 4 & 3 & 3 & 40 & 50 & 0.7423 \\
\hline 1800 & 4 & 3 & 3 & 50 & 60 & 0.7355 \\
\hline 2400 & 4 & 3 & 3 & 60 & 70 & 0.7308 \\
\hline 3600 & 4 & 3 & 3 & 80 & 90 & 0.7382 \\
\hline 4200 & 4 & 3 & 3 & 80 & 90 & 0.7372 \\
\hline 1800 & 8 & 3 & 3 & 50 & 60 & 0.8834 \\
\hline 3600 & 8 & 3 & 3 & 80 & 90 & 0.8793 \\
\hline 4200 & 8 & 3 & 3 & 80 & 90 & 0.8772 \\
\hline & & & & & & \\
\hline
\end{tabular}

\section{RESULT ANALYSIS}

In the previous research work various researchers have developed different models for rain attenuation prediction. The comparison of different important models with this proposed model is given below-

Table-II: Comparison of proposed model with different important models

\begin{tabular}{|c|c|l|}
\hline Sl No & \multicolumn{1}{|c|}{ Models } & \multicolumn{1}{c|}{ Description } \\
\hline 1. & Proposed model & $\begin{array}{l}\text { 1) This model is used to minimize } \\
\text { the Bit Error Rate in the } \\
\text { tropical region. }\end{array}$ \\
$\begin{array}{l}\text { 2) This model is applicable for 5G } \\
\text { communication frequency ranges } \\
\text { (both sub 6 GHz and mm Wave) }\end{array}$ \\
\hline
\end{tabular}

\begin{tabular}{|c|c|c|}
\hline 2. & ITU-R model & $\begin{array}{l}\text { 1) This is the Specific attenuation } \\
\text { model for rain for use in } \\
\text { prediction methods. The specific } \\
\text { attenuation } \gamma_{\mathrm{R}}(\mathrm{dB} / \mathrm{km}) \text { is obtained } \\
\text { from the rain rate } R(\mathrm{~mm} / \mathrm{h}) \text { using } \\
\text { the power-law relationship: } \\
\gamma_{\mathrm{R}}=\mathrm{KR}^{\alpha} \\
\text { 2) In the above equation the } \\
\text { values for the coefficients } k \text { and } \alpha \\
\text { are determined as functions of } \\
\text { frequency, } f(\mathrm{GHz}) \text {, in the range } \\
\text { from } 1 \text { to } 1000 \mathrm{GHz} \text {. }\end{array}$ \\
\hline 3. & Silva Mello Model & $\begin{array}{l}\text { 1) A modified method that } \\
\text { addressed some of the problems } \\
\text { found in the current ITU-R } \\
\text { method but retains the general } \\
\text { expression for } \mathrm{d}_{\text {eff }} \text { (which is the } \\
\text { basis of the model,) and uses the } \\
\text { full rainfall rate distribution at the } \\
\text { links region as input for the } \\
\text { prediction of the cumulative } \\
\text { distribution of rain attenuation } \\
\text { was proposed by Silva Mello. } \\
\text { 2) A correction factor } \mathrm{r}_{\mathrm{p}} \text { was } \\
\text { introduced to accommodate all } \\
\text { percentages of time for available } \\
\text { data with the expression: } \\
\mathrm{R}_{\mathrm{P}}=\mathrm{A} / \mathrm{KR}_{\mathrm{P}}{ }^{\alpha} \mathrm{d} \\
\mathrm{R}_{\mathrm{p}} \text { are respectively the rain } \\
\text { attenuation and the point rainfall } \\
\text { rate exceeded at } p \% \text { of the time. }\end{array}$ \\
\hline 4. & Moupfouma Model & $\begin{array}{l}\text { Similarly to the ITU-R model, the } \\
\text { prediction method proposed by } \\
\text { Moupfouma receives } \\
\text { R0.01 as the input to predict A as: } \\
\mathrm{A}(\mathrm{P})=\mathrm{KR}_{0.01}{ }^{\alpha} \mathrm{L}_{\mathrm{eq}}(\mathrm{P}, \mathrm{L}) \\
\mathrm{Leq} \text { is the equivalent path length } \\
\text { that is the product between the } \\
\text { actual path length } \mathrm{L} \text { and a } \\
\text { correction factor dependent on the } \\
\text { rain rate. } \\
\text { The above equation is valid for } \\
\mathrm{L}<=7 \mathrm{~km} \text {. }\end{array}$ \\
\hline
\end{tabular}

From the above comparison it is cleared that no other model is used to minimize the bit error rate in the tropical regions for $5 \mathrm{G}$ frequency ranges. Only the proposed model is used to minimize bit error rate for $5 \mathrm{G}$ frequency. So the proposed model is quite different than the other models and this is the importance of the proposed model.

\section{A. Synthesis Result:}




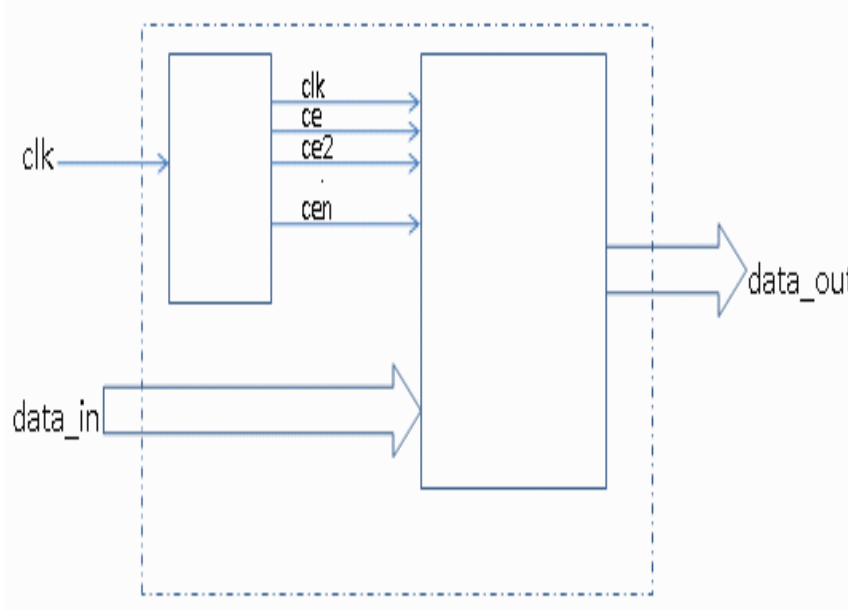

Fig. 7. Schematic diagram of convolution encoder

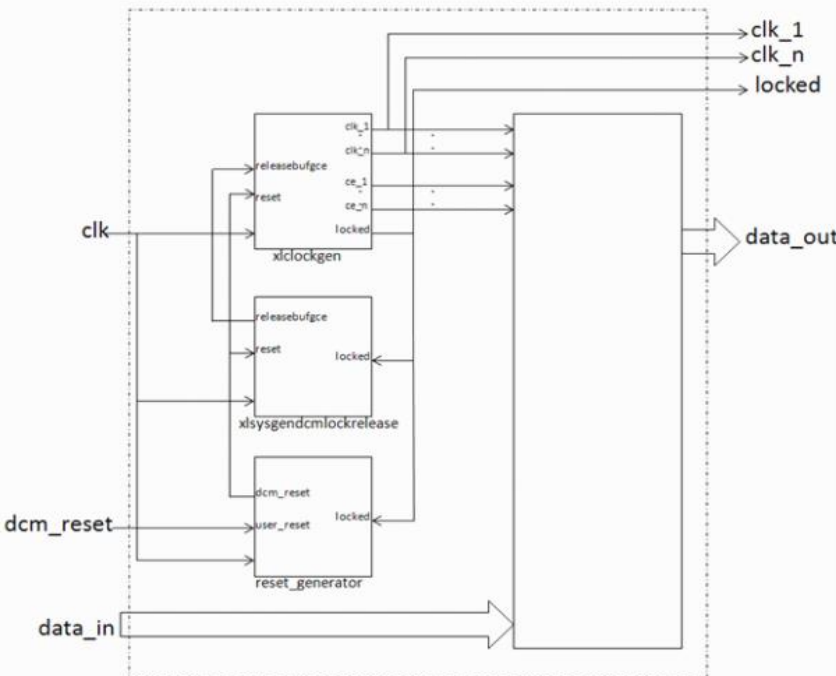

Fig. 8. Schematic Diagram of Digital clock manager

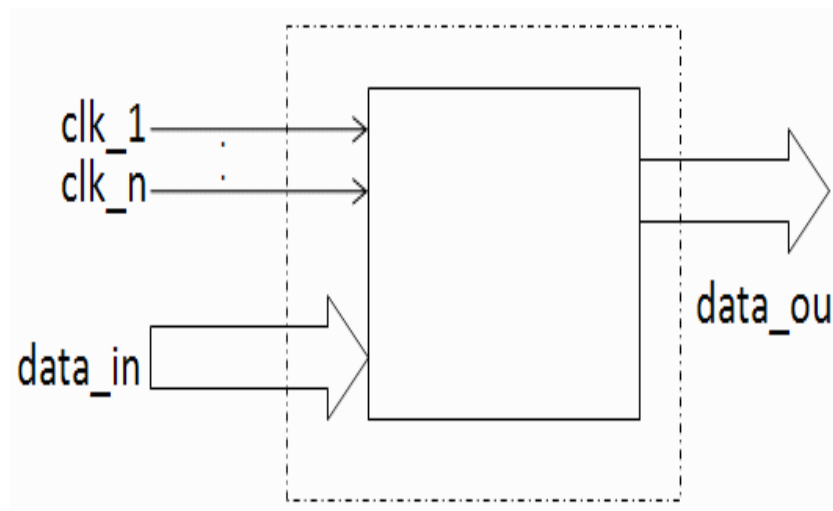

Fig. 9. Schematic Diagram of clocks

\section{B. Simulation Result}

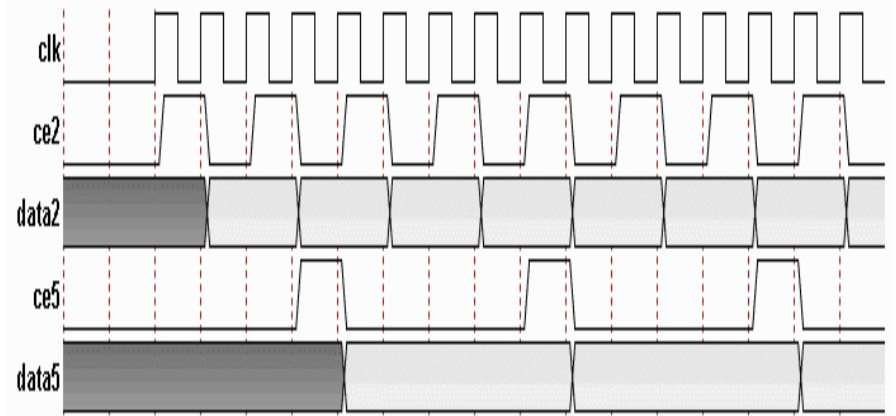

Fig.10. An example of generated clock enables in a System Generator design

The timing diagram above is an example of a System Generator design that contains three different rate domains with data periods

- $\mathbf{1}$ - Realized using the clk signal

- 2 - Realized using ce2 signal

- 5 - Realized using ce5 signal

As seen in the timing diagram, the first rising edge of ce 2 is caused by the first rising edge of the clk and this allows the flip-flops connected to ce2 to capture data on the second rising edge of the clk. Similarly, the first rising edge of ce5 is caused by the fourth rising edge of clk and this allows the flip-flops connected to ce5 to capture data on the fifth rising edge of the clk. This rule can be extended to every rate in the design. This phase has to be maintained to ensure that the design when simulated in System Generator is cycle accurate with hardware. The diagram also contains data signals - data2 and data5. These signals can either be generated by flip-flops connected to clock enable ce2 or ce5 or these signals can drive the input ports of the design. If these signals are driving input ports with normalized sample periods of 2 or 5 (refer to the Table 2 for details on the port interface of tp7_cw.vhd), then they must also align with ce2 and ce5 signals as shown in the timing diagram to be cycle accurate with the System Generator simulation model of the design.

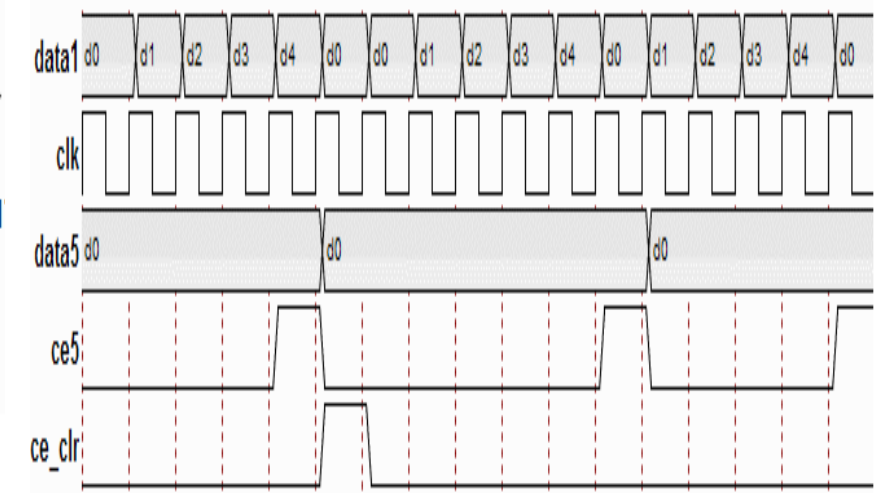

Fig.11. simulation result of convolution encoder

\section{WAVEFORM}




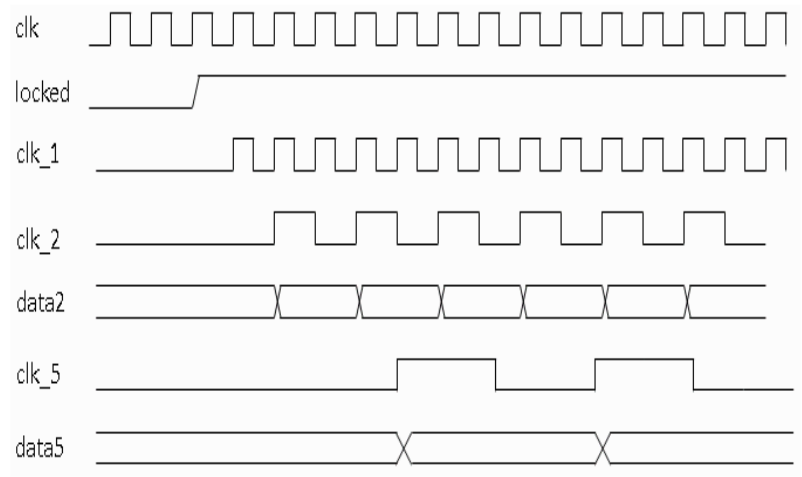

Fig.12. Simulation Result of Digital Clock Manager

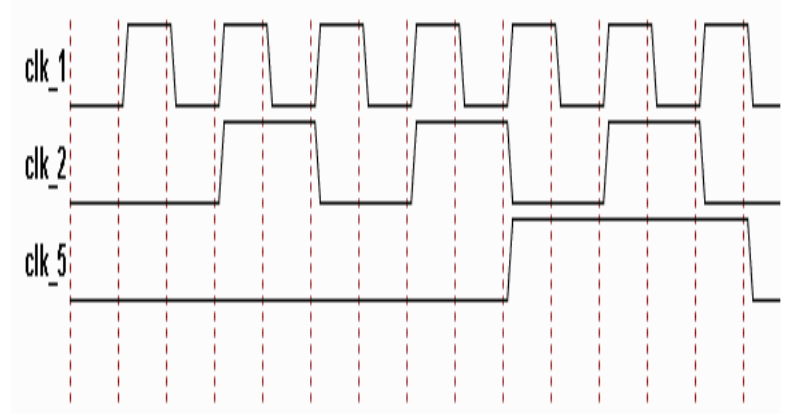

Fig.13. Simulation Result of clock

This document is generated from a Xilinx System Generator for DSP (System Generator) design. The purpose of the document is to specify the interface of this design. Each of the subsequent sections provides details on the port interface, signal timing, design files, design statistics and design environment.

\section{Port Interface}

This section has put documents of the port interface of tp7. All the Gateway In and Gateway Out blocks in a System Generator design are translated to top-level input and output ports. System Generator Type refers to the type of signals emanating from Gateway Ins and driving Gateway Outs. Type refers to one of the following -

- Data :Signals that are synchronized to Clock

- Clock: Clock signal for the design. All operations of the core are synchronized to the rising edge of the Clock signal

- Clock Enable: Clock Enable signal is attached to the clock enable pins of flip-flops. A valid clock signal occurs only when Clock Enable Signal attached to CE pin of flip-flops is high on a rising clock edge. If CE is Low, the flip-flops are held in their current state.

Period refers to the sampling period of a particular signal. Please refer to the section below on Multi-rate Realization for more details.
Table- III: Top level port interface

\begin{tabular}{|l|l|l|l|l|l|l|}
\hline Name & $\begin{array}{l}\text { Direc } \\
\text { tion }\end{array}$ & $\begin{array}{l}\text { HDL } \\
\text { Type }\end{array}$ & Type & $\begin{array}{l}\text { System } \\
\text { Generator } \\
\text { Type }\end{array}$ & Period & $\begin{array}{l}\text { Com } \\
\text { ment }\end{array}$ \\
\hline ce & in & std_logic & $\begin{array}{l}\text { Clock } \\
\text { Enable }\end{array}$ & - & - & \\
\hline clk & in & std_logic & Clock & - & - & \\
\hline $\begin{array}{l}\text { gatewa } \\
\text { y_in }\end{array}$ & in & std_logic & Data & Bool & 1 & \\
\hline $\begin{array}{l}\text { gatewa } \\
\text { y_in1 }\end{array}$ & in & std_logic & Data & UFix_1_0 & 1 & \\
\hline $\begin{array}{l}\text { gatewa } \\
\text { y_in2 }\end{array}$ & in & std_logic & Data & UFix_1_0 & 1 & \\
\hline $\begin{array}{l}\text { gatewa } \\
\text { y_out }\end{array}$ & out & $\begin{array}{l}\text { std_logic_ } \\
\text { vector (1 } \\
\text { downto 0) }\end{array}$ & Data & UFix_2_0 & 1 & \\
\hline $\begin{array}{l}\text { gatewa } \\
\text { y_out1 }\end{array}$ & out & std_logic & Data & Bool & 1 & \\
\hline
\end{tabular}

\section{Design Files}

System Generator creates a number of design files to assist in compiling the design all the way down to a bit stream. The Figure below gives an overview of the structural connectivity in the top-level module tp7_cw. This section also provides information on each of the files that are produced when the System Generator design is net listed to create its HDL representation.

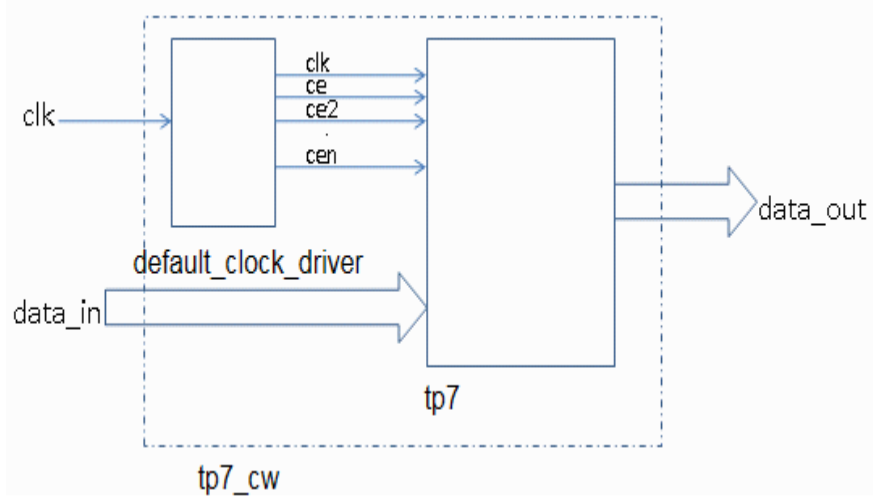

Fig.14. Structural connectivity of the top-level module tp7_cw

Table- IV: HDL files included in the design

\begin{tabular}{|c|l|}
\hline HDL file & \multicolumn{1}{|c|}{ Description } \\
\hline tp7_cw.vhd & $\begin{array}{l}\text { This is the top level module. This is a HDL wrapper } \\
\text { for the design. Depending on the type of multi-rate } \\
\text { implementation selected it drives the clock enables } \\
\text { in the design or clocks. }\end{array}$ \\
\hline tp7.vhd & This contains most of the HDL for the design. \\
\hline tp7_tb.vhd & $\begin{array}{l}\text { This is a test bench that wraps the design. When } \\
\text { simulated in ModelSim/lSim, this test bench } \\
\text { compares simulation results from Simulink against } \\
\text { those produced by ModelSim/lSim }\end{array}$ \\
\hline
\end{tabular}

Table-V: Files included in the design

\begin{tabular}{|c|l|}
\hline File & \multicolumn{1}{c|}{ Description } \\
\hline tp7_cw.ise & $\begin{array}{l}\text { This allows the System Generator created netlist to be } \\
\text { brought into the Xilinx project management tool Project } \\
\text { Navigator. }\end{array}$ \\
\hline
\end{tabular}




\begin{tabular}{|l|l|}
\hline xst_tp7.scr & XST script file specifies the XST compilation option. \\
\hline xst_tp7.prj & $\begin{array}{l}\text { XST project file specifies the HDL file compilation } \\
\text { order. }\end{array}$ \\
\hline isim_tp7.prj & $\begin{array}{l}\text { ISIM project file specifies the HDL file compilation } \\
\text { order. }\end{array}$ \\
\hline vcom.do & $\begin{array}{l}\text { ModelSim do file specifies the HDL file compilation } \\
\text { order. }\end{array}$ \\
\hline vsim.do & $\begin{array}{l}\text { ModelSim do file specifies the ModelSim simulation } \\
\text { commands. }\end{array}$ \\
\hline tp7.sgp & This is a system generator project file by the ISE project. \\
\hline
\end{tabular}

\section{E. Design Statistics}

The table below contains the settings on the system generator token used to generate the design

Table -VI: Compilation options

\begin{tabular}{|l|l|}
\hline \multicolumn{1}{|c|}{ Options } & \multicolumn{1}{c|}{ Settings } \\
\hline Compilation Target & HDL Netlist \\
\hline Part & Xc7k325t-3fbg900 \\
\hline Hardware Description Language & Vhdl \\
\hline Synthesis Tool & XST \\
\hline Multirate Implementation & Clock Enables \\
\hline
\end{tabular}

The table below lists all the System Generator blocks used in constructing the design and number of instances of each of the blocks. It also indicates IP versions that are used by the block and the license types of each of the IP.

\section{F. Tools}

The table below lists the tools and their versions used to generate this design.

Table-VII: Block Utilization Summary

\begin{tabular}{|l|l|c|l|}
\hline \multicolumn{1}{|c|}{ Block Type } & LogiCORE IP & $\begin{array}{c}\text { Number of } \\
\text { Instances }\end{array}$ & $\begin{array}{c}\text { IP } \\
\text { License }\end{array}$ \\
\hline $\begin{array}{l}\text { Xilinx } \\
\text { Convolution } \\
\text { Encoder 7.0 }\end{array}$ & $\begin{array}{l}\text { Convolution } \\
\text { Encoder 7.0 }\end{array}$ & 1 & No \\
\hline $\begin{array}{l}\text { Xilinx Gateway } \\
\text { In }\end{array}$ & & 3 & No \\
\hline $\begin{array}{l}\text { Xilinx Gateway } \\
\text { Out }\end{array}$ & & 2 & No \\
\hline $\begin{array}{l}\text { Xilinx System } \\
\text { Generator }\end{array}$ & & 1 & No \\
\hline $\begin{array}{l}\text { Xilinx viterbi } \\
\text { Decoder 7.0 }\end{array}$ & Viterbi Decoder 7.0 & 1 & No \\
\hline
\end{tabular}

\begin{tabular}{|c|c|}
\multicolumn{2}{c}{ Table-VIII: Tool versions } \\
\begin{tabular}{|c|c|}
\hline Tool & Version \\
& \\
\hline ISE Design Suite & 14.5 \\
\hline MATLAB/Simulink & $8.3 .0 .532(\mathrm{R} \mathrm{2014a})$ \\
\hline
\end{tabular}
\end{tabular}

\section{CONCLUSION}

The 5G communication model as depicted can be inserted in the wireless communication in the hope that it may unfurl a new horizon enveloped in the mystery of rain of the tropical regions for benefit of people of those regions. The communication link based on the above diversity model (fig 6) has been implemented in anticipation that it can bring about a significant change in the region of wireless communication. This model can be very helpful to minimize
Bit Error Rate (BER) and signal fading for 5G communication in the tropical regions where heavy rainfall occurs. The frequency range ranges from $600 \mathrm{MHz}$ to 100 $\mathrm{GHz}$. Using this model the signal attenuation can be diminished and as a result a signal of better quality can be achieved at the receiver.

\section{REFERENCES}

1. R. Crane: Prediction of Attenuation by Rain, IEEE Transactions on Communications vol.28, No-9, pp.1717-1733, 1980.

2. D. Panagopoulos; P.D.M.; Arapoglou; G.C. Panayotis: Satellite communications at $\mathrm{Ku}, \mathrm{Ka}$ and $\mathrm{V}$ Bands: Propagation impairments and mitigation techniques .IEEE Communications Surveys and Tutorials, 2004.

3. M. Tamrakar; K. Bandyopadhyay; A. De,: Comparison of Rain Attenuation Prediction Models with Ku-Band Beacon Measurement for Satellite Communication System .IEEE international conference on signal processing and communication (SPCOM), Bangalore, India, pp. 18-21,July 2010.

4. D. Das; A. Maitra: Rain attenuation prediction during rain events in different climatic regions. J. Atmos. Solar -Terr. Phys. Vol.128 No-1, pp.1-7, 2015.

5. M. R. Clay; A.P. Lenham: Transmission of Electromagnetic Radiation in Fogs in the 0.53-10.1 $\mu \mathrm{m}$ Wavelength Range .Appl. Opt. vol.20,No-22,pp. 3831-3832,1981.

6. B. R. Strickland; M.J. Lavan.; E. Woodbridge, et al.: Effects of Fog on the Bit-Error Rate of a Free-Space Laser Communication System .Appl. Opt. vol. 38 No.-3, pp. 424-431, 1999.

7. R. Nebuloni; and C. Capsoni: Effect of AdverseWeather on FreeSpace Optics .Optical Wireless Communications: Signals and communication Technology, Springer International Publishing, Switzerland, 2016.

8. S. A. Callaghan; B. Boyes; A. Couchman, et al.: An investigation of site diversity and comparison with ITU-R recommendations. Radio Sci. vol.43, No.4, pp. 1-8, 2008.

9. J. S. Ojo; M. O. Ajewole; S. K. Sarkar: Rain rate and rain attenuation prediction for satellite communication in ku and ka bands over Nigeria .Progress in Electromagnetics Research B 5, pp.207-223, 2008.

10. K. Ulaganathen; T.A. Rahman; S.K.A. Rahim, et al.: Review of Rain Attenuation Studies in Tropical and Equatorial Regions in Malaysia: An Overview .Antennas and Propagation Magazine, IEEE, vol.55, No.1, 2013.

11. J.S. Mandeep: $0^{\circ} \mathrm{C}$ isotherm height for satellite communication in Malaysia. Advances in Space Research vol.43, No 6, pp. 984-989, 2009.

12. R. Nalinggam; W. Ismail; M. J. Singh, et al.: Development of rain attenuation model for Southeast Asia equatorial Climate .Communications, IET, vol.7 No.10, pp. 1008-1014, 2013.

13. J.S. Mandeep; K. Tanaka: Effects of atmospheric parameters on satellite link .Int J Infrared Milli Waves vol. 28, pp.789-795, 2007.

14. Z. Yun; M.F. Iskander: Ray tracing for radio propagation modeling: principles and applications .IEEE Access 3, pp.1089-1100, 2015.

15. X. Yin; C. Ling; Kim, M.-D.: Experimental multipath-cluster characteristics of 28-GHz propagation channel .IEEE Access 3, pp. 3138-3150 2015

16. J.C. Aviles; A. Kouki: Exploiting site-specific propagation characteristics in directional search at $28 \mathrm{GHz}$.IEEE Access, 4, pp.3894-3906, 2016.

17. X. Yin; Y. Ji.; H. Yan: Measurement-Based Characterization of 15 $\mathrm{GHz}$ Propagation Channels in a Laboratory Environment. IEEE Access 5, pp.1428-1438, 2017.

18. M. Marzuki; T. Kozu.; T. Shimomai, et al.: Diurnal variation of rain attenuation obtained from measurement of raindrop size distribution in equatorial Indonesia .IEEE Transactions on Antennas and Propagation vol.57, No.4, pp.1191-1196, 2009.

19. L. S. Kumar; Y. H. Lee; J. T. Ong: Truncated gamma drop size distribution models for rain attenuation in Singapore .IEEE transactions on antennas and propagation vol.58 No.4, pp. 1325-1335, 2010.

20. S.Shrestha1; D.-Y. Choi: Rain attenuation over terrestrial microwave links in South Korea .IET Microwaves, Antennas \& Propagation vol.11No.7, pp. 1031-1039, 2017. 
21. P. Watson; N. McEwan: Cross polarisation, attenuation and radar reflectivity studies at X-band. Final report submitted to the ESRO under contract, 2044/73MD (1974).

22. A. Hirata; T. Kosugi; H. Takahashi. et al.: 120-GHz-Band Wireless Link Technologies for Outdoor 10-Gbit/s Data Transmission .IEEE Transactions on Microwave Theory and Techniques vol.60 No.3,pp. 881-895, 2012

23. A. Hirata; R. Yamaguchi: H. Takahashi: Effect of Rain Attenuation for a 10-Gb/s 120-GHz-Band Millimeter-Wave Wireless Link .IEEE Transactions on Microwave Theory and Techniques 57 (12), 30993105 (2009).

24. I. Kallfass; F. Boes; T. Messinger. et al.: 64 Gbit/s Transmission over 850 m Fixed Wireless Link at $240 \mathrm{GHz}$ Carrier Frequency .Journal of Infrared, Millimeter, and Terahertz Waves vol.36 No.2,pp. 221-233 ,2015.

25. K. Zheng; L. Zhao; J. Mei et al.: $10 \mathrm{~Gb} / \mathrm{s}$ hetsnets with millimeterwave communications: access and networking-challenges and protocols .IEEE Communications Magazine 53 (1), 222-231(2015).

26. L.D.S. Mello; M. S. Pontes: Unified method for the prediction of rain attenuation in satellite and terrestrial links .Journal of Microwaves, Optoelectronics and Electromagnetic Applications vol.11, No.1, pp. 114, 2012

27. F. J. A. Andrade; A. A. M. D. Medeiros; L. A. R. d. s. Mello: ShortTerm Rain Attenuation Predictor for Terrestrial Links in Tropical Area IEEE Antennas and Wireless Propagation Letters pp.1325$1328,2017$.

28. L. Luini; C. Capsoni: The SC EXCELL model for prediction of rain attenuation on terrestrial radio links. Electronics Letters vol.49 No.4, pp. 307-308, 2013.

29. L. Zhao; Q. Song; C. Zhao, C. et al.: Rain Attenuation Prediction Models of $60 \mathrm{GHz}$ Based on Neural Network and Least SquaresSupport Vector Machine. The Proceedings of the Second International Conference on Communications Signal Processing, and Systems, Cham: Springer International Publishing, 2014.

30. R. Ghiani, L. Luini; A. Fanti: A physically based rain attenuation model for terrestrial links. Radio Science vol.52 No.8, pp. 972-980, 2017.

31. A.I. Yussuff; N. H. Khamis; Modified itu-r rain attenuation prediction model for a tropical station .Journal of Industrial and Intelligent Information vol.1,No-3, 2013.

S. Shrestha; D.-Y. Choi: Rain attenuation statistics over mm wave bands in South Korea .Journal of Atmospheric and SolarTerrestrial Physics vol.152, pp. 1-10, 2017.

32. K. Ulaganathen; I.M. Rafiqul, T.A. Rahman et al.: Monthly and diurnal variability of rain rate and rain attenuation during the monsoon period in Malaysia .Radio Engineering vol.23 No.2, pp. 754-757,2014.

33. S. Sun; T.S. Rappaport; R. W. Heath et al.: MIMO for millimetrewave wireless communications: Beamforming, spatial multiplexing, or both? IEEE Commun. Mag. vol.52, No.12, pp.110-121, 2014.

34. S. Han; L.I. Chih. ; Z. Xu: Large-Scale antenna systems with hybrid analogue and digital Beamforming for millimetre wave 5G. IEEE Commun .Mag vol.53, No.1, pp. 186-194, 2015.

35. I. Shayea; T. A. Rahman; M.H. Azmi; A. Arsad: Rain attenuation of millimetre wave above $10 \mathrm{GHz}$ for terrestrial links in tropical regions, pp.1-27, 2018.

36. I. Shayea; T.A. Rahman; M.H. Azmi; M.R. Islam: Real Measurement Study for Rain Rate and Rain Attenuation Conducted over $26 \mathrm{GHz}$ Microwave 5G Link system in Malaysia, pp.1-21, 2018.

\section{AUTHORS PROFILE}

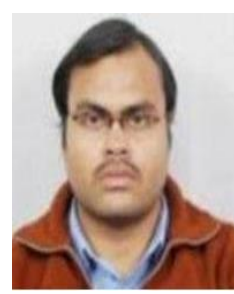

Trilochan Patra has obtained his B.Tech and M.Tech degree from MCKV Institute of Engineering under Maulana Abul Kalam Azad University of Technology, W.B India (Formerly known as West Bengal University of Technology) in 2009 and 2011. $\mathrm{He}$ is working as an assistant professor in ECE Department in Techno International Newtown (Formerly known as Techno India College of Technology) from 2011.His interested research area is Wireless communication, Microwave Communication etc. Email:trilochanpatra266@gmail.com

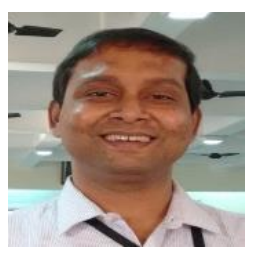

Swarup Kumar Mitra received his B. Tech degree from kalyani University, India in 2000. He has achieved his M.Tech in VLSI Design and Microelectronics technology from Jadavpur University, India in 2007. He is attached as associate professor in ECE in MCKV Institute of Engineering, Liluah, and Howrah, India and awarded with $\mathrm{PhD}$
(Eng.) 2012 from Jadavpur University. His present research area is wireless sensor network and its architecture etc. 